\title{
Embedded Pragmatic Effects and Conversational Implicatures
}

\section{Joanna Odrowąż-Sypniewska' ${ }^{1}$}

Received: 2 February 2019 / Accepted: 21 May 2019 / Published online: 29 May 2019

(c) The Author(s) 2019

\begin{abstract}
In a recent paper Mandy Simons has argued that in a Gricean framework there is room for embedded pragmatic effects. One of her goals has been to demonstrate that an argument put forward by François Recanati to the effect that it is not possible to apply Gricean reasoning to generation of local pragmatic effects is mistaken. In his commentary Recanati maintains that the view suggested by Simons can be called Gricean only in a very broad sense and insists that the process responsible for local effects is essentially different from the one which generates conversational implicatures. In my view their exchange highlights important issues concerning the way in which local pragmatic effects are generated and is worthy of a careful analysis. In what follows I critically examine Simons's and Recanati's views and then suggest the view that in the light of this analysis seems to me the most adequate. In particular, I argue - against Recanati-that during the interpretation process interpreters construct literal propositional nuclei, which usually fell short of being truth-evaluable but which play an important role in the interpretation. I claim that the view that assumes that such literal propositions are constructed in the process of interpretation is more universal and may be used to analyse a wider range of examples than the view that does not postulate such constructions. Nevertheless, I maintain-against Simons - that the global and local pragmatic inferences are importantly different.
\end{abstract}

Keywords Conversational implicature $\cdot$ Embedded pragmatic effect · Grice . Gricean framework - Literal proposition - Make as if to say · Recanati - Simons · What is expressed - What is said

Joanna Odrowąż-Sypniewska j.odrowaz@uw.edu.pl

1 Institute of Philosophy, University of Warsaw, Warsaw, Poland 


\section{Introduction}

In a recent paper Mandy Simons (2017a) has argued that in a Gricean framework there is room for embedded pragmatic effects. Although she does not claim that local pragmatic effects are conversational implicatures, ${ }^{1}$ she argues that a similar mechanism that is at work when implicatures are generated can be used to generate local effects. One of her goals has been to demonstrate that an argument put forward by François Recanati to the effect that it is not possible to apply Gricean reasoning to generation of local pragmatic effects (Simons 2017a: 471; Recanati 2003: 89-90) is mistaken. In his commentary (on which Simons also comments) Recanati maintains that the view suggested by Simons can be called Gricean only in a very broad sense and insists that the process responsible for local effects is essentially different from the one which generates conversational implicatures. In my view their exchange highlights important issues concerning the way in which local pragmatic effects are generated and is worthy of a careful analysis. In what follows I'll first analyse Simons's and Recanati's views and then suggest the view that in the light of this analysis seems to me the most adequate. In Sect. 2 I briefly summarise the view suggested by Simons. ${ }^{2}$ Section 3 contains an overview of Recanati's assessment of her proposal and in particular of her critique of his earlier argument. In Sect. 4 I formulate some doubts concerning the way in which Recanati's view should be understood (Sect. 4.1). I indicate that on the view presented by him in his 2017 paper it is no longer clear whether literal propositions are not calculated in the process of interpreting sentences like "The ham sandwich has left without paying". I also point out that the notion of what is expressed proposed by Simons to replace what is said cannot play the role she intended for it (Sect. 4.2). Moreover, I suggest a view according to which during the interpretation process interpreters construct literal propositional nuclei, which usually fell short of being truth-evaluable but which play an important role in the interpretation (Sect. 4.3). I argue that the view that assumes that such literal propositions are constructed in the process of interpretation is more universal and may be used to analyse a wider range of examples, than the view that does not postulate such constructions. In Sect. 5 I defend Simons's view from the charge formulated by Recanati that it is not Gricean, because it does not sufficiently distinguish saying and making as if to say. I do not think this charge is fair, but I do have doubts concerning Simons's claim that her solution is truly global. If it is not, then it cannot be regarded as Gricean after all $^{3}$ (but for a different reason than the one

\footnotetext{
1 Simons considers this as one of the available options, but she does not favour this view. See Simons 2017a: 479. Nb. Huang (2018) claims that embedded pragmatic effects (and other unarticulated constituents) are neo-Gricean pre-semantic conversational implicatures. Simons-following strictly Gricean tradition-claims that there cannot be any pre-semantic implicatures and thinks of embedded pragmatic effects as conversational implicitures.

2 I'll limit myself here only to the issues relevant for the interpretation of embedded pragmatic effects and ignore many other interesting topics that are raised in this exchange.

3 I ought to mention that Simons considers several views in her papers and some of them are less Gricean than others. In particular she suggest a view that allows the application of Gricean maxims to sub-sentences, i.e. a view that manifestly is not global. But I'll ignore this version here and focus on the more conservative one.
} 
suggested by Recanati). Finally, in Sect. 6 I present the view of generating embedded pragmatic effects that I take to be the most adequate. My view assumes-contrary Recanati-that literal propositions (scil. propositional nuclei) are constructed in the course of interpretation, but I claim-contrary to Simons and like Recanatithat the difference between local and global inference is important.

\section{Simons: Gricean Local Pragmatics}

In her recent papers Simons argues that local pragmatics can be fitted into a Gricean framework. According to her, despite the fact that embedded effects are pragmatic in nature, they can be accounted for within classical Gricean account. For her embedded pragmatic effects are implicitures rather than conversational implicatures, but she claims that the mechanism that generates implicatures can be adapted to calculate such effects as well. Hence, Gricean framework is capable of accounting for "non-implicature pragmatic effects" (Simons 2017a: 469).

Simons says that it is constitutive of any Gricean conception that it rests on two pillars. One pillar is that the goal of the interpreters is to identify the speaker's communicative intention. The second pillar is the assumption that speakers are reasonable both in their choice of communicative goals and in their choice of "linguistic means to accomplish [those] goals" (Simons 2017a: 469). In addition she distinguishes embedded pragmatic effects from embedded pragmatic computation. Embedded pragmatic effects are defined as cases in which "the propositional content which falls under the scope of a linguistic operator (...) includes content which is the output of pragmatic inference" (Simons 2017a: 470), whereas embedded pragmatic computation is a computation in which general pragmatic principles (such as Gricean maxims) are applied to the content of unasserted embedded clauses. Simons argues that embedded pragmatic effects do not involve embedded pragmatic computation. She maintains that interpreters have access to the contents of unasserted embedded clauses but they do not apply general pragmatic principles to them, which allows her to argue that her account remains Gricean. According to her the standard Gricean model of deriving an implicature consists of two steps: it begins with Gricean reasoning which consists in a realisation that the principle of cooperativity (or at least one of the maxims) has prima facie been violated and leads to the Gricean conclusion that the speaker must have meant something different from what she said. In the second-interpretative-step the hearer tries to establish what the speaker really meant. No truly Gricean account can allow the content of unasserted embedded clauses to play any role at the first step, but Simons argues that such content may be used in the interpretative step. She demonstrates that local pragmatic enrichment in many cases is a result of applying Gricean maxims globally, to the content of whole speech acts. One of the examples that she discusses is the following:

A: What's making noise up in the attic?

B: Either there's a nest up there, or some squirrels have moved in (Simons 2017a: 473). 
The intended enrichment here is that the nest in question is an occupied nest. Simons notices that a disjunctive answer to question is felicitous only if each of the disjuncts can be interpreted as a felicitous answer. Thus in this case the hearer would notice that the disjunctive answer as a whole apparently violates the maxim of relevance and would also recognize that this is due to the fact that it is the first disjunct which violates this maxim. The hearer would then come to the conclusion that the speaker must have meant something different. In the interpretative step she would arrive at the conclusion that "nest" has to be enriched to mean "occupied nest". What gets enriched is the content of the disjunct but the maxim of relevance is applied to the disjunction as a whole. Thus the solution is local, but the problem is global (Simons 2017a: 473).

\section{Recanati: Embedded Pragmatic Effects are not Gricean}

One of Simons's goals was to show that Recanati's argument against the possibility of Gricean account of embedded pragmatic effects (Recanati 2003: 89-90) is mistaken. If it is possible to account for embedded pragmatic effects without applying Gricean maxims at the local level, then such an account is compatible with a Gricean framework, contrary to what Recanati has claimed.

In his reply Recanati argues that embedded pragmatic effects might be called Gricean only in a very broad sense in which any account which appeals to the recognition of communicative intentions and assumes the cooperative principle (CP) is Gricean (Recanati 2017: 494). However, if we suppose that to be Gricean an analysis must consist of two stages: semantic stage in which the interpreter establishes what was said and the pragmatic stage in which the interpreter infers what the speaker really means by what she said, then the account that Simons proposes is not Gricean. In the pragmatic stage the hearer takes what is said as an input, assumes that the speaker is obeying the CP and infers the speaker's intended meaning. Recanati stresses that the calculation of the intended meaning is on this picture post-propositional, since it relies on the prior determination of what is said (Recanati 2017: 494). As we've seen, Simons claims that this two-stage model applies to embedded pragmatic effects, but Recanati argues that this is no so. He maintains that even if we allow that literal proposition plays a role in a rational reconstruction of the hearer's inference, it is not the case that pragmatic modulation is a result of a global inference which starts from the fact that the speaker has said something that is not compatible with his observing Gricean maxims. According to Recanati the interpreter's inference consists of two parts which he calls a triggering inference (which corresponds to Simons's Gricean reasoning leading to a Gricean conclusion) and a generating inference (this is Simons's interpretative step). Recanati is willing to agree with Simons that the triggering inference is global, but insists that the generating inference is entirely local in the case of embedded pragmatic effects such as modulation. According to him the generating stage (i.e. the stage at which the intended meaning is generated) is very different in the case of implicatures and in the case of embedded pragmatic effects. The premise stating what the speaker literally said is 
used at the triggering stage in both cases, but only in the former case is this premise appealed to at the generating stage:

In pragmatic modulation cases, the generating mechanism which is needed to yield the correct interpretation is not (and cannot be) a global inference-it has no use for the premise that the speaker has said what she has said (Recanati 2017: 503).

Recanati argues that cases of pragmatic modulation are similar to cases of the substitution type, which Grice includes into conversational implicatures, but which for Recanati are too different to be so categorized. According to him the generating inference for genuine conversational implicatures "in a nutshell" looks like this: “the speaker's utterance implicates that $q$ because (1) the speaker says that $p,(2)$ she observes the $\mathrm{CP}$, and (3) her saying that $p$ violates the CP unless $q$ " (Recanati 2017: 504). Thus, to give a noncontroversial example, the speaker's answer "I have to study for the exam" to the question "Shall we go to the cinema tonight?" implicates that the speaker cannot go to the cinema tonight because (1) the speaker says that she has to study for the exam, (2) she observes the CP and in particular the maxim of relevance, and (3) her saying that $p$ violates the $\mathrm{CP}$ unless she cannot go to the cinema tonight. Recanati calls this "a recipe for calculating conversational implicatures" (Recanati 2017: 503) and notices that substitution cases, such as irony or metaphor, do not fit this pattern. If after Peter played a dirty trick on John, John says sarcastically "Peter is a fine friend", we cannot use this recipe to infer the implicature that Peter is a bad friend. The problem here is that one cannot say that John said (in the Gricean sense) that Peter is a fine friend, for John doesn't mean that Peter is a fine friend. In the previous case the speaker means both the proposition literally uttered (that she has to study) and the proposition implied (that she cannot go to the cinema). The fact that she intends to imply that she cannot go to the cinema saves the original utterance from being irrelevant. In the second case, the proposition "Peter is a fine friend" still violates the CP, for it is blatantly false. In order to show that the speaker is nevertheless observing the $\mathrm{CP}$, the inferred content has to replace rather than supplement the original content. Since John doesn't mean that Peter is a fine friend we have to say that he only makes as if to say this (in Gricean terminology). In such cases the interpreter has to find an alternative proposition and substitute it for the original one, but in doing this he has no recipe to follow and is left on his own. That is why Recanati says that "it is a mistake to see the standard notion of conversational implicature as covering this type of case, to which the Gricean recipe does not apply" (Recanati 2017: 505).

The pragmatic modulation cases are like the substitution cases: the pragmatically enriched meaning has to be substituted for the literal meaning. "There is a nest up there" should be read as "There is an occupied nest up there", "The ham sandwich left without paying" as "The ham-sandwich-orderer left without paying" and "There is an old lion in the piazza" either as "There is an old statue of a lion in the piazza" or "There is a statue of an old lion in the piazza". To infer those meanings we do not follow the Gricean recipe, but instead 
[t]he strategy here is one of reconstrual. As a result of the triggering inference, the interpreter knows that what the speaker means must be some proposition alternative to the proposition literally expressed. To identify that proposition, the strategy is to go through the process of semantic composition once again, while giving to some constituent in the sentence a modulated meaning distinct from its literal meaning (Recanati 2017: 505).

In the process of reconstrual a local processes of modulation take place. They are local in the sense that they determine contents of the constituents of the proposition (see Recanati 2017: 506). Those modulated contents together with contents of other constituents compose the intended meaning of the utterance. Since local enrichment process does not presuppose a prior computation of a proposition, Simons in her reply objects that on Recanati's view "local pragmatics has a magical flavor" (Simons 2017b: 549). She argues that if the interpreter does not construct the proposition first, it is unclear how she knows what pragmatic modulation is needed. She also complains that although Recanati probably thinks of the process as context-sensitive, "it is not clear what the contribution of context is understood to be" (Simons 2017b: 550, fn. 8).

\section{Literal Propositions}

\subsection{The Role of Literal Propositions in Recanati's View}

I do not think it is fair to accuse Recanati of postulating magical processes. Although in the paper to which Simons refers, Recanati doesn't describe the modulation process in much detail, in his earlier writings he does depict the process and explains the way in which local pragmatic enrichment processes are sensitive to context. For instance in "The alleged priority of literal interpretation" (1995), while discussing the example "The ham sandwich has left without paying" Recanati says that firstly for the hearer the literal interpretation of the "ham sandwich" is more accessible, but after she processes the meaning of the predicate "has left without paying" the ham-sandwich-orderer becomes more accessible and it is this last semantic value which undergoes composition and forms a proposition with the semantic value of the predicate. The accessibility shift is caused by the meaning of the predicate alone and although the literal interpretation of "the ham sandwich" is initially the one that is most accessible to the interpreter it is nevertheless never combined with the meaning of the predicate. Recanati insists that:

The interpreter does not go from the concept of ham sandwich to that of ham-sandwich-orderer after having entertained the absurd literal proposition; rather it is because the interpreter goes from the concept of ham sandwich to that of ham-sandwich-orderer (as a result of an accessibility shift resulting from the interpretation of the predicate) that he or she does not entertain the absurd literal proposition (Recanati 2004: 33). 
Although in my opinion local enrichment is described in sufficient detail in Recanati's earlier works, I have to admit that it is not clear whether he still adheres to this view in his reply to Simons. On the one hand, in 2017 paper as in his earlier ones (see e.g. Recanati 2004: 29), he says that the proposition literally expressed need not "be actually computed in the course of interpreting the utterance" (Recanati 2017: 499). He also admits that the literal proposition might play a role in rational reconstruction, which is of course consistent with the previous remark. On the other hand, however, three pages later he says that he agrees with Simons that

a pragmatic inference to the intended meaning can be triggered globally by e.g. the absurdity of the literal meaning of the utterance undergoing interpretation, even though the effect resulting from the pragmatic inference is the local substitution of a non-literal (e.g. pragmatically enriched) interpretation for the literal interpretation of some constituent in the sentence (Recanati 2017: 502).

Moreover, when describing the triggering inference (which-as I've already mentioned-corresponds to Simons's Gricean reasoning) Recanati says that it "appeals to the fact that the speaker's locutionary act is not prima facie compatible with the presumption of cooperativity, and concludes that what the speaker means must differ from what he says" (Recanati 2017: 502). He also admits that the triggering inference is global but insists that it is of no consequence for the question of whether embedded conversational implicatures are possible (see Recanati 2017: 503), for the reason why such implicatures are not possible is the fact that the generating inference is not global and-contrary to the triggering inference-makes no use of the premise concerning what the speaker has said. Independently of whether or not we agree with the claim that the generating inference is not global, what should strike us in this description is the very existence of the triggering inference. If that inference is global, uses the premise that the speaker has said what she said and its conclusion is that the speaker must mean something different, then it appears that the literal proposition has been computed after all. On the view suggested in Recanati's comment on Simons the difference between interpreting "I have to study for the exam" as an answer to "Shall we go to the cinema tonight?" and "The ham sandwich has left without paying" is confined to the generating inference. In both cases the triggering inference will be the realization that since what the speaker said apparently violates the $\mathrm{CP}$, she must mean something different from what was literally said. If this is so, than Recanati can no longer insist that the proposition literally expressed is not computed during the interpretation. One might try saying that the triggering inference is only part of a rational reconstruction rather than part of an actual interpretation process, but this seems utterly implausible. One cannot posit a triggering inference that activates a further generating inference and in the same breath claim that it is not actual. In addition, the realization that the speaker must mean something different from what she has said appears to be a very real part of our everyday speech interactions also in cases of modulation. ${ }^{4}$ Moreover, Recanati himself seems to admit that

\footnotetext{
4 In particular, in the case of "The ham sandwich has left without paying" the literal interpretation is clearly accessible to interpreters.
} 
the prior computation is actual. As we have seen, he claims that the strategy in the substitution cases like the "ham sandwich" case is one of "reconstrual" and in order to identify the proposition meant by the speaker the interpreter has to "go through the process of semantic composition once again" (Recanati 2017: 505-my emphasis), which clearly presupposes that one went through that process before. ${ }^{5}$

\subsection{Simons's What is Expressed}

In her reply to commentators, ${ }^{6}$ Simons argues that "Grice should never have taken what is said as a starting point for pragmatic inference" (Simons 2017b: 542). She suggest that that starting point should be what is expressed, where this last notion is understood as in Searle (1965, Section 3). Expressing $p$ means roughly the same as making as if to say that $p,{ }^{7}$ i.e. when one expresses that $p$ one does not have to intend to commit that $p$ (see Simons 2017b: 541). What is expressed is "a truthevaluable proposition closely related to the conventional meaning of the sentence uttered" (Simons 2017b: 546). We obtain what is expressed by taking the conventional meaning of the expressions uttered, fixing the reference of indexicals and carrying out composition (see Simons 2017b: 545). In her reply to commentators Simons adds that local pragmatic enrichment is "separable from the conventionally encoded content of the utterance" (Simons 2017b: 557) and "do not necessarily contribute to truth conditional content" (Simons 2017b: 559). Thus if A asks "What's making noise in the attic?" and B replies "There is a nest up there", the proposition expressed by B is just that there is a nest in the attic. If later on A and B go up to the attic and discover an old, disused nest there, B might correctly say "Well, I was right-there is a nest up there" (Simons 2017b: 557). Thus, the picture that Simons is offering seems to be a four-layered one: (1) lexical meaning, (2) what is expressed, (3) what is said, (4) what is implicated. ${ }^{8}$

One of the main disagreements between Simons and Recanati concerns the role of what is said. Recanati assumes that what is said has to be a starting point of generating implicatures. The substitution cases, such as modulation and irony, do not count as implicatures because what is said does not play the required role in their interpretation. As a result Recanati thinks that Grice has made a mistake in making room for

\footnotetext{
5 The only way out would be to say that the triggering inference is not part of the 'proper' course of interpreting the utterance, which consists only in the interpretative inference. Such a move however is arbitrary and in addition the picture it suggests is implausible. If one were to accept this, one would have to deny that literal interpretation of the utterance counts as a part of the process of overall interpretation.

6 Other comments on Mandy Simons's paper were written by Robyn Carston and Emma Borg (both in the same issue of Inquiry).

7 Simons defines "make as if to say" as follows: "to make as if to say $p$ is to utter a linguistic expression whose conventional meaning, relative to the context of utterance, is $p$, where the utterance is intended as a communicative act". Simons 2017b: 543.

8 This is a view common to semantic minimalists (see Recanati 2004). What differentiates Simons from minimalists like Emma Borg, is the claim that it is 2. rather than 3. that is the starting point of pragmatic inference generating conversational implicatures.
} 
what is made as if to say in his theory of conversational implicatures. Simons also thinks that Grice has made a mistake, but a very different one: he shouldn't have taken what is said as a starting point of pragmatic inference and should have concentrated on what is expressed (made as if to say) instead. For Simons it is crucial to allow what is made as if to say to be the starting point, because the whole project of assimilating local and global inferences hinges on this. Simons's view faces a serious problem, however. For in many cases it is simply not true that the starting point of generating implicatures is what is expressed rather than what is said. Only in cases in which there is no what is said do we revert to what is made as if to say. For instance, in the very example cited above, if A were to interpret what B implicates with his utterance, he would not start with "There is a nest up there" but with "There is an occupied nest up there". Clearly the implicature is that the birds are making the noise, and there is no way to derive that implicature from the existence of a disused nest. ${ }^{9}$ Thus, it is not the case that "a position where we take conversational inference to begin from what is expressed is not so far from the position that Grice laid out" (Simons 2017b: 542). Replacing what is said with what is expressed would seriously distort Gricean framework.

\subsection{Literal Propositional Nuclei}

In my view it is implausible to assume that a literal full-blooded truth-evaluable proposition (like "The ham sandwich has left without paying from the place p (i.e. the place at which this utterance is made) at a time $t$ (i.e. recent time prior to this utterance)" is actually entertained by the interpreter in the course of interpreting the utterance "The ham sandwich has left without paying". The time and the place are left in the situation of the utterance, however I think that the interpreter does compose the "The ham sandwich has left without paying" part. The interpreter constructs the literally expressed proposition (presumably adding the most accessible semantic value for "the ham sandwich" to the meaning of "has left without paying"), realizes that this cannot be what the speaker has meant and looks for an alternative proposition. "The literal proposition" is actually a misnomer, for more precisely it is something that might be called 'propositional nucleus ${ }^{10}$ and which needs to

\footnotetext{
${ }^{9}$ Unless one wants to regard "There is an occupied nest in the attic" as a conversational implicature. This is an option that Simons considers in the first of her papers, but ultimately she chooses another. Huang does claim that such effects are implicatures. One of his reasons for taking them to be implicatures rather than implicitures is that according to him there is no reliable test that could distinguish alleged implicitures from implicatures. He mentions Recanati's availability principle and the CohenRecanati scope principle, but claims that neither works. See Huang 2018: 23-24. Paradoxically, however, he analyses local effects as neo-Gricean pre-semantic conversational implicatures, i.e. such that their generation does not rely on what is said (or made as if to say). Hence, in Simons's terminology they count as implicitures, not implicatures.

10 I'm calling it "propositional nucleus" rather than "propositional radical" in order not to forejudge the issue of whether or not it is the same notion as Kent Bach's. Bach insists that his propositional radicals are not propositions ("An incomplete proposition is no more a proposition than a sentence fragment is a sentence or a rubber duck is a duck" Bach 2006: 439). But after the rise in popularity of relativist 'propositions' I think I'm justified in calling "propositions" my propositional nuclei. Nb. propositional nuclei are enough to answer Simons's charge concerning "magical flavor" (see above) and are in accord-
} 
be supplemented from the context before it becomes truth-evaluable On Recanati's view the interpreter entertains the sandwich-meaning of "the ham sandwich", then entertains the meaning of "has left without paying", notices that it applies to people and without composing the absurd proposition backtracks and replaces the sandwich-meaning with the orderer-meaning. Thus, the only difference between my proposal and Recanati's stance is that in the first instance the absurd combination is constructed, whereas in the second-it is not. It is worth noticing however that the "construction" in this case means only putting the semantic values of "the ham sandwich" and "has left without paying" together.

Thus, the difference comes down to modulation being due to the absurdity of "the ham sandwich has left" in one case and to processing the meaning of "has left" without combining it with the literal meaning of "ham sandwich" in the other case. If we put it like this, the difference doesn't seem all that significant, nevertheless it appears that for many examples Recanati's picture is less plausible than the alternative one. It is true that in the case of "The ham sandwich has left without paying" we realize that the predicate applies only to humans just by focusing on its meaning. In many cases however, the interpretation is not that straightforward.

First of all, some utterances admit of at least two interpretations. As Recanati notes, "The city is asleep" may either mean that the inhabitants of the city are asleep (metonymical interpretation of "the city") or that the city is quiet (metaphorical interpretation of "asleep"). If the interpreter assumes the literal meaning of "the city", the meaning of "asleep" will be non-literal and vice versa (Recanati 2004: 34). According to Recanati this is an illustration of the fact that interpreters search for coherent interpretations, in which the constituents fit one another (Recanati 2004: 36). Two semantic values $\alpha$ and $\beta$ fit together if $\langle\alpha, \beta>$ instantiates an abstract schema:

in a sentence like 'The city is asleep', if we give to 'asleep' its literal value (thereby activating the SLEEP schema), the value of 'the city' will have to be of the relevant type (for example, human or animal), hence non-literal. (Recanati 2004: 36).

Thus the choice of one value 'coerces' the choice of another (ibid.). The other interpretation will consist in giving 'the city' its literal value (presumably activating the CITY schema), and thereby forcing the value of "asleep" to be non-literal. So we have two schemas available: the schema SLEEP <inhabitants of the city; asleep> and the schema CITY < the city; being quiet> and probably the context makes one of them more accessible than the other. All this is perfectly consistent with the view presupposing a prior actual construction of a literal proposition. The only difference between the views is that one postulates an additional preliminary step: calculation of the literal proposition, while on the other view this step is non-existent. Are there any arguments that would decide which view is the correct one? One might say that Recanati's view is more economical and the construction of the literal proposition is redundant: it plays no role in the interpretation. However, it seems to me that

Footnote 10 (continued)

ance with her claim that "pragmatic modification in principle always requires at least some compositional work" (Simons 2017b: 549). 
there is a better argument in favor of the opposite view. Take for instance another of Recanati's examples: "There is a lion in the middle of the piazza". The intended meaning is that it is a statue of a lion which is in the piazza not a real lion, thus in the process of interpretation the meaning "a statue of a lion" is substituted for "a lion". It seems clear however that (at least in some contexts) substitution takes place only after the whole "There is a lion in the middle of the piazza" has been constructed and the interpreter has realized that it is unlikely that a real lion sits there. "Is in the middle of a piazza" is a predicate that can apply both to the statue and the real lion, and the reason for choosing one interpretation over the other has to do with the unlikeliness of what is expressed rather than with its absurdity. Even more problematic for the no-literal-proposition view are cases like "The ham sandwich stinks" ham sandwich is tasty". The most accessible semantic value for "the ham sandwich" in most contexts is clearly the sandwich. When the interpreter focuses on the meaning of the predicate, he notices that it is such that it does apply to sandwiches, so it seems that there is no reason for him not to conclude that the speaker has meant to say that the ham sandwich stinks. Only at this stage the interpreter has a chance of realizing that in fact it is not likely that the speaker means this (e.g. the speaker has no direct contact with sandwiches at the moment and cannot smell them). So she will eventually conclude that the speaker means that it is the ham sandwich orderer who stinks but she will do so on the basis of considering the literal proposition "The ham sandwich stinks" which she has previously computed. Only in the very special context (e.g. waiters' talk) sandwich will not be the most accessible semantic value for "sandwich". In other contexts this will be the 'default' value for this expression and the meaning of "stinks" will give no reason to change this initial assignment. Thus, on Recanati's picture the hearer will give "the ham sandwich" and "stinks" their literal values (presumably activating the schema SMELLS) and since both those values fit together, she will construct the proposition "The ham sandwich stinks". Any further interpretations will be post-propositional. If I am right then it appears that on this view one has to say that the interpretation of "The ham sandwich stinks" and "The ham sandwich has left without paying" are importantly different (from the point of view of the advocate of such a view): one is pre-propositional while the other is post-propositional. Postulating such a difference in the interpretation of two similar statements seems counterintuitive. Needless to say, on the opposite view the interpretation of both utterances are similar (since in both cases the literal propositional nuclei is constructed in the course of interpretation).

\section{Simons's Solution: Local or Global?}

As I have mentioned above Recanati argues that substitution-type cases are too distinct from other cases of implicature to be regarded as such. He uses his considerations to claim that Simons is mistaken in trying to fit local pragmatic effects into a

11 The example is considered by Recanati, e.g. in "Contextualism and Polysemy" (dialectica 71 (2017): 379-397). 
Gricean framework. He admits that Grice did include substitution-type cases among conversational implicatures but thinks that it was a mistake on his part and attempts to correct it. Be that as it may, it does not seem fair to claim that Simons's stance is not Gricean on the grounds that her stance does not fit the corrected-Gricean view. In the well-known passage of Logic and conversation Grice defines conversational implicature in the following way:

"I am now in a position to characterize the notion of conversational implicature. A man who, by (in, when) saying (or making as if to say) that $p$ has implicated that $q$, may be said to have conversationally implicated that $q$, provided that (1) he is to be presumed to be observing the conversational maxims, or at least the Cooperative Principle; (2) the supposition that he is aware that, or thinks that, $q$ is required in order to make his saying or making as if to say $p$ (or doing so in those terms) consistent with this presumption; and (3) the speaker thinks (and would expect the hearer to think that the speaker thinks) that it is within the competence of the hearer to work out, or grasp intuitively, that the supposition mentioned in (2) is required". (Grice 1989: 30-31)

In this characterization, it is clear that the speaker may conversationally implicate $q$ by making as if to say as well as by saying that $p$. One may argue that Grice was mistaken in thinking this, but such a claim is not a ground for objecting that an account that conforms with this characterization is not Gricean. ${ }^{12}$

Having said that I have to admit that I'm not convinced by Simons's argument that it is possible to maintain that Gricean maxims are always applied globally. Simons considers examples of disjunctive and conditional utterances and argues that the interpreter applies the maxims to such utterances as wholes and as a result knows how to adjust the meaning locally. Since for the disjunctive answer to be relevant both disjuncts have to be relevant, the hearer who upon hearing such an answer realizes that it is not relevant knows that it is due to one of the disjuncts being irrelevant. Consider again:

A: What's making noise up in the attic?

$\mathrm{B}$ : Either there is a nest up there, or some squirrels have moved in.

The idea must be that the interpreter waits until she hears the whole utterance, realizes that it is a disjunction and that it is not relevant as a whole. Since the second disjunct on its own would be a relevant answer to the question, she concludes that it must be the first disjunct which is not relevant and proceeds to substitute "occupied nest" for "nest". However, it seems to me that it is very unlikely that we do reason that way and such a description is inadequate even as a mere Gricean rational reconstruction (cf. Simons 2017a, fn. 11). Imagine that instead of saying "Either there is

12 Simons makes similar remarks. See e.g. Simons 2017b: 543. 
a nest up there, or some squirrels have moved in" B just says: "There is a nest up there... or some squirrels have move in". ${ }^{13}$ This utterance is also a disjunction but one that hasn't been flagged as such. In this case the hearer will enrich "nest" to "occupied nest" as soon as she hears the first part of the utterance. She will not wait till the end of the whole sentence, because she does not yet know that the sentence is going to be a disjunction. If I'm right, then it might be argued that it is very unlikely that the uttering of "either" has such a momentous effect on the interpreter as to cause him to wait with interpreting until she hears the whole utterance. Besides, even if one insists that "either" has this effect, the utterance "There is a nest up there or some squirrels have move in" is also a disjunction, so one would have to claim that some disjunctions are enriched globally while some-locally, which endangers the project of Gricean local pragmatics.

\section{Embedded Pragmatic Effects Versus Conversational Implicatures}

As we have seen Recanati argues that the mechanism generating conversational implicatures is importantly different from the one generating embedded pragmatic effects. The former relies on the prior calculation of what is said, which is used as a premise, while the latter is pre-propositional and resembles indexical resolution. Simons, on the other hand, argues that "local and global pragmatic inferences are continuous" (Simons 2017b: 544) and there is no essential difference between them. She argues that a similar mechanism that is at work when implicatures are generated can be used to generate local effects. On the one hand, I think that Recanati is right that the processes in question are significantly different, but on the other hand, I believe that in both the literal proposition plays an important role.

In my view the literal proposition is actually computed in the course of interpreting utterances like "The ham sandwich has left without paying". As I have said I do not think that at this stage hearers construct the full truth-evaluable proposition. Rather they just combine the semantic value of the subject with that of the predicate and construct what I called "propositional nucleus". My reason for adopting the literal-proposition-first view ${ }^{14}$ is the following. I think that we get this construction 'on the cheap': it is effortless and very fast. Recanati claims that we 'inspect' the semantic values of the subject and the predicate separately and combine them only after we reach what we take to be the right interpretations (be they literal or non-literal). Such a view seems to me to ignore the fact that many of the utterances that we hear are meant to be interpreted literally. The no-literal-proposition view is well suited for the broad view of communication according to which non-literal interpretation is at least as common (and probably more common) than the literal one. From this perspective it might indeed be pointless to start with constructing literal propositions, for is unlikely that they will be the correct ones. However, my

\footnotetext{
13 An even better example is the one with the mother's birthday (Simons 2017a: 479). In an answer to the question "What will you do for your mother's birthday?" B can say "I'll buy her flowers or I'll cook a nice dinner" as well as "Either I'll buy her flowers or I'll cook a nice dinner".

14 Strictly speaking it is the literal-propositional-nucleus-first view.
} 
perspective is different. For me the literal interpretation is the default one. Recanati himself admits that the most accessible semantic values are often the literal ones. Often it suffices to combine the literal value of the subject with the literal value of the predicate to obtain the right result. In fact it seems to me that constructing such a propositional nucleus is easier and less costly for the interpreter than analyzing the values of component expressions separately. So, it seems plausible that we do it automatically in all cases and only start looking for non-literal interpretations when we see that something is not right.

On the other hand I side with Recanati when he stresses the dissimilarity between the derivation of conversational implicatures and the generation of embedded pragmatic effects. As I see it, the main difference consists in the fact that the interpreter when trying to derive implicatures assumes what has been said (or has been made as if to say) by the speaker. Whereas the whole point of the process of establishing local pragmatic effects is to determine what has been said (or has been made as if to say). Contrary to Simons, I think that the reasonings "from what is said" and "to what is said" are very different enterprises (see Simons 2017b: 544). In the former case the interpreter takes for granted what has been said and looks for something else that the speaker might have meant as well. In the latter case the interpreter realizes that the literal proposition cannot be what the speaker meant to communicate, so she backtracks and constructs the proposition anew. It should be clear that the literal proposition nucleus that the interpreter constructs in both cases might not be (and usually is not) what is said, because typically it is not a full proposition. In some cases it will be completed from context and become what is said, but in other cases it will need first to be reconstructed and then completed.

My view is different form both Recanati's and Simons's. I assume that the starting point of pragmatic inference generating implicatures might be either what is said (in most cases) or what is made as if to say. In determining what is said we need to construct literal propositional nuclei, which are different form Simons's what is expressed in that they are usually too 'thin' to be truth-evaluable. Crucially, they cannot serve as a premise in the inference generating conversational implicatures (unless they happen to be identical with what is said or made as if to say).

\section{Conclusion}

The exchange between Simons and Recanati nicely illustrates the way in which semantic minimalists and contextualists differ as far as the notion of what is said and the generation of embedded pragmatic effects are concerned. Simons does not admit to being a semantic minimalist but at least the last version of her view, which gives an important role to conventional and truth-conditional what is expressed, can safely be included among the minimalist standpoints. ${ }^{15}$ The view that I'm proposing is situated somewhere in between these two opposing views. It is not fully contextualist,

\footnotetext{
15 In particular her remarks concerning the availability of what is expressed are reminiscent of Borg's. See e.g. Borg 2004: 59.
} 
because it assumes that literal propositions (or rather propositional nuclei) play an important part in the process of interpreting utterances and arriving at what is said. However, it is not fully minimalist either, because it-like Kent Bach's viewrejects propositionalism: nuclei are usually not truth-evaluable. I think that it is a mistake to insist on the semantic values of the subject and the predicate not being combined. On the other hand, I believe that minimalists make a mistake when they insist on there being truth-conditional minimal contents that play a psychological role in the process of interpreting the utterance. In my view that role is played by propositional nuclei which may be completed from the context to form full-blooded propositions but they very rarely (if ever) are so completed. For the interpretation the propositional nucleus is entirely sufficient. The 'real' proposition is constructed only at the stage of pragmatically enriched what is said. I also think that the processes responsible for conversational implicatures and for local pragmatic effects are dfferent, but since I allow implicatures to be generated from what is made as if to say as well as from what is said, that difference is not that prominent for me as it is for Recanati.

Acknowledgements The research for this paper was possible thanks to the support of National Science Centre, Poland (grant OPUS 8; research project UMO-2014/15/B/HS1/00171). I'd like to thank the anonymous reviewer for valuable comments.

Open Access This article is distributed under the terms of the Creative Commons Attribution 4.0 International License (http://creativecommons.org/licenses/by/4.0/), which permits unrestricted use, distribution, and reproduction in any medium, provided you give appropriate credit to the original author(s) and the source, provide a link to the Creative Commons license, and indicate if changes were made.

\section{References}

Bach K (2006) The excluded middle: semantic minimalism without minimal propositions. Philos Phenomenol Res 73:435-442

Borg E (2004) Minimal semantics. Oxford University Press, Oxford

Grice JP (1989) Logic and conversation. In: Grice JP (ed) Studies in the way of words. Harvard University Press, Cambridge, MA, pp 22-40

Huang Y (2018) Unarticulated constituents and neo-Gricean pragmatics. Lang Linguist 19:1-31

Recanati F (1995) The alleged priority of literal interpretation. Cogn Sci 19:207-232

Recanati F (2003) Embedded implicatures. Philos Perspect 17:299-332

Recanati F (2004) Literal meaning. Cambridge University Press, Cambridge

Recanati F (2017) Local pragmatics: reply to Mandy Simons. Inquiry 60:493-508

Searle J (1965) What is a speech act? In: Black M (ed) Philosophy in America. Allen and Unwin, London, pp 221-239

Simons M (2017a) Local pragmatics in a Gricean framework. Inquiry 60:466-492

Simons M (2017b) Local pragmatics in a Gricean framework, revisited: response to three commentaries. Inquiry 60:539-568

Publisher's Note Springer Nature remains neutral with regard to jurisdictional claims in published maps and institutional affiliations. 